\title{
The Frontiers publishing paradigm
}

\section{Kendall A. Smith*}

Division of Immunology, Department of Medicine, Weill Medical College, Cornell University, New York, NY, USA

*Correspondence: kasmith@med.cornell.edu

Digital technology has created the possibility of a paradigm shift in scientific publishing for the first time in four centuries.

Traditional, high impact publishing largely relies on the publication of only a limited number of papers, which are highly selected by the editors and reviewers aiming at the highest "impact" on the field. As a consequence, the journal's publications may be frequently referenced by investigators in the field, much to the benefit of a journal's impact factor. In general, a high impact factor is sought after by the publishers and scientists alike as the gold standard of the excellence of the journal, promoting the widest distribution of new findings to the scientific community and essentially giving the publisher a reputation without regard to any individual articles. For a restrictedaccess journal, a high impact factor is of course further desirable to promote subscriptions and advertising, and eventually ensure a lucrative return. In a way, the traditional restricted-access system of scientific publishing is geared to reject submitted papers, forcing a bet between the high cost of printing what may be a "mediocre" scientific article and the assignment of a high impact factor which translates directly into revenue. Most of the highest impact journals publish only $\sim 10 \%$ of the papers submitted for review, and proudly tout these numbers as a sign of their exclusivity. For example, Science states that "Because of the stiff competition for space in the journal, Science now accepts less than $8 \%$ of the original research papers submitted. About $80 \%$ of submitted manuscripts are rejected during an initial screening stage by the Staff Editors and the Board of Reviewing Editors" (see Science info for authors - FAQ).

In this author's opinion, this system of peer review is flawed. In order to reduce the number of manuscripts sent for review, so as to reduce the workload, editors who are not, or no longer, practicing scientists, make the editorial decision whether to send a paper for review. This decision is often driven by the familiarity of the editor with the topic or the fame of the authors of the manuscript, and not necessarily based on a thorough reading and understanding of the contents of the paper. Accordingly, many submitted papers do not make it past this first "cut."

A manuscript that does make it into the review system can easily become the victim of politics within the scientific community, as the reviewers and authors are often directly competing groups. The reviewer then wields formidable power in rejecting or delaying the acceptance of a manuscript as long as possible, making the time interval from submission to eventual publication over 1 year. The reviewers may request additional experiments and data for completely valid scientific reasons to improve the manuscript, but do not necessarily realize that at some point the authors are forced to compromise the quality of the figures or clarity of the explanations in order to still abide by journal-imposed length restrictions. This has led to supplementary online material (SOM) flourishing over the past decade, with one of my own recently submitted manuscripts weighing in at more than 85 pages.

The pointless irony of all these flaws in the traditional restricted-access publishing system is that everything is based on an outdated business model of the print technology. The question we must ask ourselves is whether we can evolve from the established "restricted-access," reader-funded publishing practice to an "open access," authorfunded publishing industry managed by scientists themselves by leveraging the internet age. In this regard, it is noteworthy that the costs of publishing with Frontiers are equivalent to the "page charges" levied by the traditional restricted-access publishers.

In the Frontiers review process, authors submit their manuscripts to the Associate Editors, who assign two Review Editors for most manuscript types. These editors are charged with evaluating and certifying, in the most rigorous way, the accuracy of articles to ensure the dissemination of as much of the total amount of scientific information as possible. To facilitate this process, the Frontiers review forum has been designed to foster interaction between authors and review editors, with the overall goal of improving the manuscript - rather than finding flaws with the intention to reject. This renders the peer review process interactive and author-friendly for the first time. Review Editors are responsible for the validating the flawlessness of the experiments performed and data presented, and for the legibility and clarity of the manuscript. If the Review Editors have uncovered issues with the manuscript, the Review Editors communicate anonymously in a blog-style discussion forum with the authors to resolve the issues. If a consensus is reached with the issues resolved to the satisfaction of both of the Review Editors and the authors, the Associate Editor can accept the manuscript.

One important departure from the traditional publishing system is that if the manuscript is accepted and published, the reviewers' names are also published, thereby ensuring reviewer transparency and objectivity. This is the point where the Frontiers publishing paradigm shifts $180^{\circ}$ from the old-fashioned traditional publishing methods. The editors are charged with using their experience and expertise to improve the manuscript to the stage where it is acceptable for publication, and not to simply reject it out of hand! However, if the issues cannot be reconciled to the satisfaction of everyone, then the manuscript is rejected and the reviewers remain anonymous to the authors.

Obviously, quantity does not equal quality, and researchers entrenched in the traditional publishing paradigm are often initially suspicious that the author-pay open access model will fail to safeguard quality. Scientific reputations are, after all, derived from the quality as well as the quantity of one's publications, and therefore, the reputations of both authors and Frontiers are on the line. Accordingly, 
Frontiers has adopted the motto of The New York Times, "All the news fit to print," so that Frontiers in Immunology will accept and publish "All the science deserved to be known!"

Another growth of the grassroots Frontiers publishing paradigm is the tiered publishing system, a democratic meritocracy highlighting the quality of individual papers deemed important by the entire community of scientists. Article-level metrics based on actual views and downloads replace the journal-level impact factor that is calculated from the number of references to the entire journal. Authors can follow their own papers' Impact Stats from the date of acceptance. Over the first 6 months after publication, the number of times an individual paper is accessed, and the number of times it is downloaded, is tracked electronically. The authors of the most accessed original research from the first tier, meaning the Specialty Journals, are effectively electronically nominated by the article tracking numbers to write a "tier 2 " article on the same subject, but geared toward a broader audience and thus placing the findings in a broader context. This Focused Review would be published on the general Frontiers in Immunology site, and not in a specialty section. The Reviewers and Editor of this prestigious article are then also invited to submit a Frontiers Commentary on the article, which is also featured in Frontiers in Immunology. In other words, the whole community of scientific peers - rather than the publisher's editorial staff - democratically selects the highest quality papers for recognition based on actual readership.

The quality of a Frontiers paper is also ensured by the policies of the construction of the manuscript, as "space" is no longer limited. SOM is kept to a minimum and consists of material that should be in an appendix, such as equations or nucleotide sequence data, and not simply additional text, data, and figures. This allows the authors to place all relevant data and figures in the main body of the paper, so that the reader can easily access and understand the figures, as well as the text. Accordingly, it is the authors' care in telling a full story and their creativity in the construction of the figures/tables illustrating it that earn recognition, and not simply what prestigious high impact journal in which the final paper appears.
For all of these reasons, publishing in Frontiers in Immunology promises to be an enjoyable and useful experience for authors. Ever since scientific publishing began in the seventeenth century, we have been at the mercy of the publishers. Like Rock and Roll artists, we have written the songs and sung the songs, but then we have given up ownership of our creative efforts to the record companies, which have controlled their distribution. Moreover, the traditional publishing companies have charged us for publishing our songs, as well the readers, and then walked away with the proceeds! No more! Frontiers authors retain the copyright to their own work. Just like Steve Jobs revolutionized the music industry with the iPod and iTunes, publishing with Frontiers promises to revolutionize scientific communication!

Received: 27 October 2011; accepted: 04 January 2012; published online: 24 January 2012.

Citation: Smith KA (2012) The Frontiers publishing paradigm. Front. Immun. 3:1. doi: 10.3389/fimmu.2012.00001 This article was submitted to Frontiers in T Cell Biology, a specialty of Frontiers in Immunology.

Copyright (c) 2012 Smith. This is an open-access article distributed under the terms of the Creative Commons Attribution Non Commercial License, which permits noncommercial use, distribution, and reproduction in other forums, provided the original authors and source are credited. 